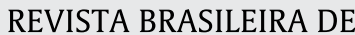

\section{Termiticide activities of wood extractives of Ziziphus mauritiana (Rhamnaceae) against subterranean termites under field conditions}

\author{
Sumer Zulfiqar ${ }^{1}$, Sohail Ahmed ${ }^{1}$, Muhammad Sufyan ${ }^{1}$, Muhammad Arshad ${ }^{1}$, \\ Ahmad Nawaz ${ }^{1}$ and Babar Hassan ${ }^{1}{ }^{2 *}$ (]) \\ ${ }^{1}$ University of Agriculture Faisalabad Department of Entomology, Faisalabad 38000, Pakistan \\ ${ }^{2}$ South China Agricultural University, Red Imported Fire Ant Research Center, Guangzhou 510642, China
}

\section{A R T I C L E I N F O}

\section{Article history:}

Received 16 September 2019

Accepted 19 December 2019

Available online 31 January 2020

Associate Editor: Eliana Cancello

\section{Keywords:}

Natural products

Wood preservation

Environment friendly

Termite

Wood extracts

\begin{abstract}
A B S T R A C T
Synthetic wood preservatives are the causes of large-scale environmental pollution and few have been withdrawn from the commercial markets in the past years. The present studies focused on determination of naturally present extractives of Ziziphus mauritiana as less toxic wood protectant against subterranean termites. Firstly, natural resistance of $Z$. mauritiana heartwood against termite was determined by exposing stakes in the field. For the preparation of extractives, air-dried $Z$. mauritiana heartwood and bark shavings were soaked in 1 liter each of ethyl acetate, hexane, petroleum ether and water in a bottle separately. Different dipping treatment times (36 and 72 hours) at 10, 20 and 30\% concentrations of extractives on Populus deltoides wooden stakes were used and stakes were exposed to termites in submerged manner. Combination of extractives in different solvents were included as separate experiment and finally, seasoning prior to extractives application on $P$. deltoides wooden stakes was also done and stakes were arranged in three replications for each treatment. Maximum mean percent weight loss $(81.1 \%)$ was observed in case of $P$. deltoides followed by boiled $Z$. mauritiana $(15.24 \%)$ in termite resistance test. Stakes treated with petroleum ether extracts had minimum weight loss alone or in combination with other extract's solvent in all experiments. Extractives in other solvents followed petroleum ether non-significantly but were significantly different from their respective control treatment, which had the highest weight loss (>60\%). Transferring durability using extracts of $Z$. mauritiana increased resistance of non-durable $P$. deltoides against termites and extractives could be used as wood preservatives.
\end{abstract}

\section{Introduction}

Subterranean termites are a major pest of human structures throughout tropical and sub-tropical regions, causing billions of dollars in damage to timber-in-service worldwide (Ahmed and French, 2008). Thirteen species of termites out of pool of fifty were identified as pests of constructions in rural and urban areas of Pakistan, which had caused economic losses. Subterranean termites are considered one of the most destructive termites in in Pakistan and the economic loss to timber in service by termites constitutes the greatest problem compared to other wood-destroying insects in the country (Hassan, 2017; Hassan et al., 2018c).

The trend for the management of termite using chemicals has changed over recent years because of environmental concerns. Wood extractives from resistant tree species have been realized as alternatives to water and oil borne wood preservatives since latter are being suspected for

\footnotetext{
* Corresponding author.

E-mail: sialuaf@gmail.com
}

environmental concerns due to persistent effect and hazardous to applicators as well (Lee et al., 2018). Severe soil contamination has been reported because of traditional wood preservation activities using creosote, copper chromium arsenate (CCA) and pentachlorophenol (PCP) (Ottosen et al., 2002). Number of plant extractives including oils, waxes, resins, tannins and/or polyphenols, are toxic and thus not only inhibit the growth of saproxylic but also of other wood degrading organisms resulting in lower rates of wood decay. Usually heartwood is more resistant than the sapwood due to its higher lignin content, density and to the presence of certain biocide substances (Bajraktari et al., 2018). These extractives can replace chemicals currently used in wood preservation. Previously, stem wood extractives of Albizia lebbeck, Tectona grandis, Dalbergia sissoo, Cedrus deodara, Pinus roxburghii, Morus alba and Morus nigra have been demonstrated to reduce weight loss in treated wooden stakes under field conditions against subterranean termites (Hassan et al., 2017a; Ahmed et al., 2018; Hassan et al., 2019a, b, c). 
Besides extracts / extractives, plant oils have anti-feedant and growth regulating effects on termites (Islam et al., 2009).

Almost 100 species of deciduous shrubs and trees belong to Genus Ziziphus, Family Rhamnaceae, which grow well in tropical and subtropical areas of the World. Some species, like $Z$. mauritiana occurs in almost every green continent. Ziziphus spp. survive on extremely drought conditions and are excellent source for natural vegetation in deserts of Indo-Pak (Razi et al., 2014). Leaf phenolic extracts of $Z$. mauritiana was effective for controlling Aedes mosquitoes by decreasing fecundity, fertility and adult life span (Devi and Bora 2017). Betulinic acid, a terpenoid, from bark of $Z$. mauritiana showed growth inhibition of Spodoptera litura and Tribolium confusum (Lingampally et al., 2012; Badathu et al., 2014). Crude methanolic extract of $Z$. jujuba showed significant termiticide activity against Heterotermes indicola and proved itself as potent source of cytotoxic drugs (Ahmad et al., 2011). Oil of Ziziphus mauritiana has high larvicidal potency against the $3^{\text {rd }}$ larval instar of Culex pipiens (El-Husseiny et al., 2014). Oil of Z. jujuba also showed significant reduction in insect sex ratio, egg hatchability in C. pipiens (El-Husseiny and Ei-Kholy, 2015).

However, there is little information about toxicity of Ziziphus wood extractives against insect pests especially termites. Ziziphus is not reported termite resistant but is not found susceptible to it as far as scientific literature is concerned. Evaluation of tree wood sensitivity towards the termites is not fully explored. Therefore, the objective of this study was to evaluate efficacy and toxicity of wood and bark extractives isolated in polar and non-polar solvents against subterranean termites.

\section{Materials and methods}

\section{Wood source and preparation of samples}

Heartwood logs and bark of Ziziphus mauritiana(Ber) and a sapwood log of Populus deltoides were purchased from Timber Market located at Jhang Road, Faisalabad. Wooden stakes of $P$. deltoides and Z. mauritiana were prepared for anti-termite bioassays under field conditions using electric saw. Wooden stakes measuring 130L x 50T x 20R mm (LTR = longitudinal, tangential and radial) were excised from heartwood of Z. mauritiana and sapwood of $P$. deltoides logs. Logs were with no observable sign of infection by mold or wood-destroying fungi and termite.

\section{Confirmatory test for resistance of Z. mauritiana}

A preliminary test to determine potential termiticide in $Z$. mauritiana wood extractives, a set of four wooden stakes were dipped into hot water in a water bath set at $80^{\circ} \mathrm{C}$ for 12 hours. Before dipping, moisture contents of stakes were determined by oven dry method. Dipped stakes were taken out and dried and weighed to pretreatment moisture contents. These stakes were tied using cable with fresh wooden stakes of similar dimension ( $130 \times 50 \times 20 \mathrm{~mm}$ LTR) from $Z$. mauritiana in the following order: fresh-boiled-fresh, boiled-fresh-boiled, freshboiled, fresh and boiled. Tied stakes (in triplicate) were placed in termite-infested soil pits already prepared for this purpose (Ahmed et al., 2014; Hassan et al., 2019a). Briefly, concrete soil pits $(0.48 \times 0.32 \mathrm{~m}$ wide and $0.40 \mathrm{~m}$ deep) were built inside Entomological Research Laboratories, at Post Graduate Agriculture Research Station, University of Agriculture Faisalabad, Pakistan. Pit floor was cemented leaving a border enough for the entrance of termites and to prevent rodents. Top of the pit was covered with iron sheet and soil was lined around the corners of iron top to seal it from rain. Soil pits were constructed in vicinity of subterranean termite nest as evidenced by the presence of nymphs in poly (vinyl chloride) corrugated monitoring pipes having cardboard as a bait (Ahmed et al., 2014). The wood specimens were placed horizontally on the cemented floor for experiments. Three fresh stakes of $P$. deltoides ( $130 \times 50 \times 20 \mathrm{~mm}$ LTR) served as positive control treatment. Wooden stakes of all kinds were sampled after 90 days and wood weight loss was determined by following formula:

Weight $\operatorname{loss}(\%)=(W 1-W 2) / W 1$

Where, $\mathrm{W}_{1=}$ Initial weight of stake; $\mathrm{W}_{2=}$ Final weight of stake.

\section{Preparation of Extractives}

Air-dried Z. mauritiana heartwood and bark were converted into wood shavings using a planner separately. A total of $250 \mathrm{~g}$ of heartwood and bark shavings were soaked in 1 liter each of ethyl acetate, hexane, petroleum ether and water in a bottle separately which was shaken at regular intervals for 20 days. After filtration, solvents were evaporated through rotary evaporator. Three concentrations (10\%, 20\%, and 30\%) of solid material in the respective solvents were prepared to test the termiticidal properties.

\section{Treatment of P. deltoides wood with extractives of Z. mauritiana}

P. deltoides wooden stakes were treated by dipping ( 36 and 72 hours) with different concentrations (10\%, 20\%, and 30\%) of Z. mauritiana heartwood and bark extractives separately. Treated stakes were offered to pre-invited termites in soil pits (partially buried in the pits as described above) in three replications for each treatment and only solvent treated stakes were controls. Data were taken after 60 days and weight loss of stakes was determined by above mentioned formula.

\section{Treatment of P. deltoides wood with combined extractives of Z. mauritiana}

Extractives from four solvents were combined in the following fashion in 1:1 ratio $(\mathrm{w} / \mathrm{w})$. Ethyl acetate + petroleum ether; Hexane + ethyl acetate; Hexane + petroleum ether; Water + petroleum ether; Water + ethyl acetate; Water + hexane. Stakes of $P$. deltoides were dipped in concentration (30\%) of each combined extractive of Z. mauritiana bark and heartwood for 36 and 72 hours. Treated stakes were offered to pre-invited termites in the pits (as described above) and weight loss was calculated after 60 days exposure.

\section{Efficacy of extractives on oven dried woods of P. deltoides}

Wooden stakes of $P$. deltoides were dried at $80^{\circ} \mathrm{C}$ for 7 days. Stakes were soaked in each of water, n-hexane, petroleum ether and ethyl acetate extractives for 72 hours from heartwood and bark extractives separately. Treated stakes along with control treatment were placed in soil pits infested with termites as in above experiments and after 60 days, wood weight loss was determined.

\section{Statistical analysis}

Completely Randomized design was used to conduct field experiments and data were analyzed using Analysis of variance test. Means were separated at the 5\% level of significance using Tukey's HSD in GraphPad Prism software. 


\section{Results}

Differences of mean percent weight loss of different combinations of fresh and boiled $Z$. mauritiana along with $P$. deltoides as positive control after 90 days of exposure to subterranean termites is presented in Fig. 1. Weight loss of $P$. deltoides (positive control) was maximum followed by boiled $Z$. mauritiana. While consumption of wood from combinations; fresh + boiled + fresh, boiled + fresh + boiled, fresh + boiled, fresh and boiled $Z$. mauritiana was significantly low $(\mathrm{F}=135.9$; $\mathrm{p}<0.01)$, but not significantly different from one another. Maximum mean percent weight loss (81.1\%) was observed in case of $P$. deltoides followed by boiled $Z$. mauritiana (15.24\%). While non-significant mean \% weight losses of 1.65, 5.12, 4.53 and, 3.3.1 in fresh + boiled + fresh $Z$. mauritiana, boiled + fresh + boiled $Z$. mauritiana, fresh+ boiled $Z$. mauritiana, boiled $Z$. mauritiana, fresh $Z$. mauritiana, respectively, were recorded. $P$. deltoides and boiled $Z$. mauritiana were susceptible to termite attack

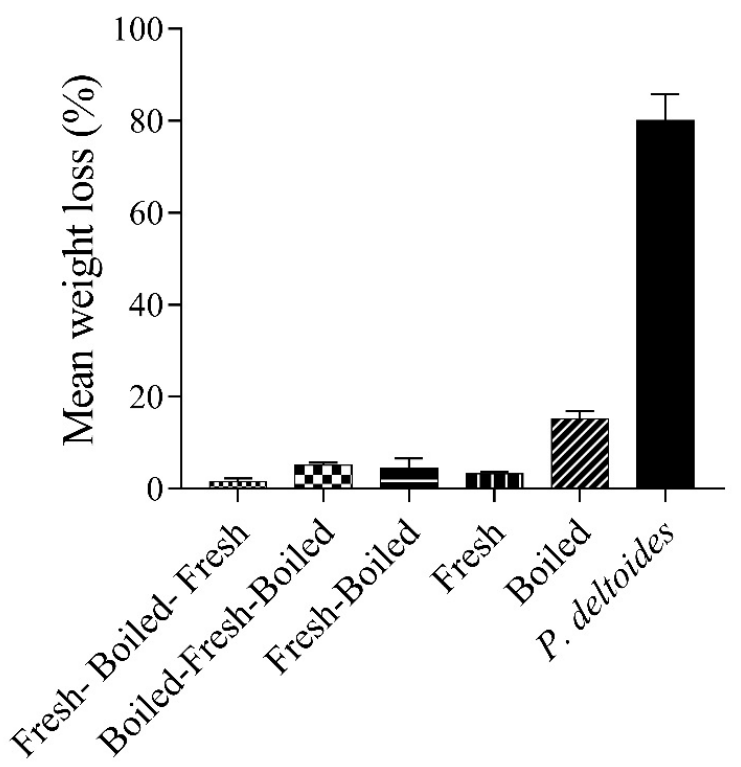

Figure 1. Comparison of mean weight loss (\%) of Z. mauritiana and $P$. deltoides under choice and no-choice test after 60 days exposure to subterranean termites. as compared to woods from fresh and boiled $Z$. mauritiana combinations and fresh $Z$. mauritiana only.

Regarding results of extractives treatments, there was significant difference in weight loss of $P$. deltoides wood dipped for $36 \mathrm{~h}$ in heartwood extractives in each concentration $(F=62.41 ; p<0.0001)$ and each type of extractives ( $F=10.8 ; p<0.01)$. Similarly, wood dipped for $72 \mathrm{~h}$ in heartwood extractives also showed significant difference in each concentration $(F=43.25 ; p<0.0001)$ and each type of extractives $(F=3.086 ; p<0.04)$. Maximum percentage of weight loss $(68.94 \%)$ was observed in control treatment of petroleum ether, which was not significantly different from other control treatments. Minimum weight loss $(22.41 \%)$ was observed in wooden stakes treated with water extractives from heartwood at concentration of $30 \mathrm{mg} \mathrm{ml}^{-1}$. Concentrations of all solvents had non-significant difference among themselves as compared to control treatments for woods treated for $36 \mathrm{~h}$ and $72 \mathrm{~h}$. Water extractives was followed by ethyl acetate, petroleum ether and n-hexane extractives in effectiveness after 36 and 72 hours of dipping (Fig. $2 \mathrm{AB}$ ). There was no significant effect of dipping time on wood weight loss of $P$. deltoides after treatment with heartwood extractives ( $F=0.90 ; p=0.78$ ).

In case of bark extractives, there was no-significant difference in wood weight loss of $P$. deltoides after treatment for $36 \mathrm{~h}(F=0.58$; $p=0.68)$ and $72 \mathrm{~h}(F=0.91 ; p=0.44)$ with bark extractives in different solvents. There was no-significant difference among concentrations of each type of extractives in performance except control treatment when wood dipped for $36 \mathrm{~h}(F=317 ; p<0.0001)$ and $72 \mathrm{~h}(F=67.35 ; p<0.0001)$ (Fig. $3 \mathrm{AB}$ ). Maximum percentage weight loss ( $>70 \%$ ) was observed in control treatments while minimum percentage weight loss $(<10 \%)$ was observed in wooden stakes treated with different concentration of extractives from each solvent except at $30 \%$ concentration of petroleum ether extract. All concentrations had non-significant differences among themselves (Fig. $3 \mathrm{AB}$ ). There was no significant effect of dipping time on wood weight loss of $P$. deltoides after treatment with bark extractives $(F=2.06 ; p=0.15)$.

Among extractives type (heartwood vs bark), there was significant less weight loss of $P$. deltoides stakes was observed after treatment with bark extractives compared to all type of heartwood extractives $(\mathrm{p}<0.05)$ (data not shown).

Percent weight of poplar wooden stakes dipped in different combination (water + hexane, hexane + petroleum ether, hexane + ethyl

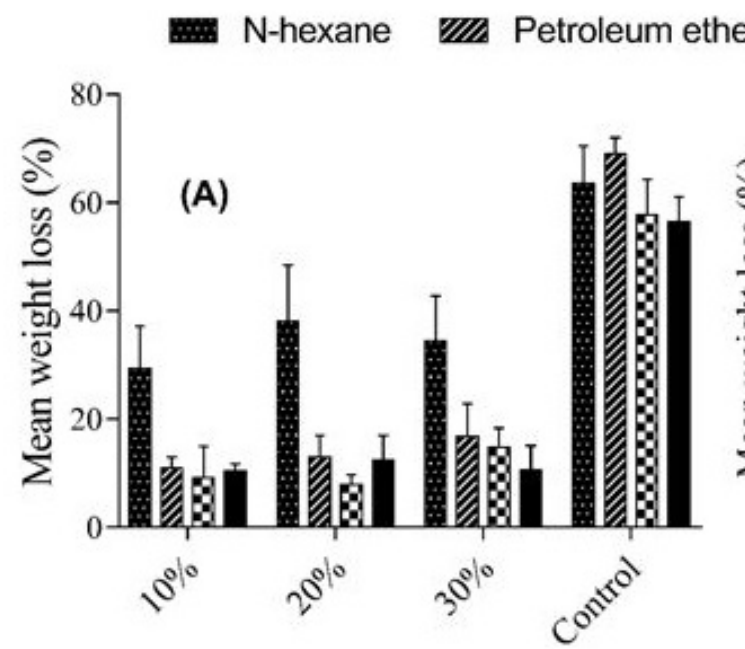

Concentration of heartwood extractives

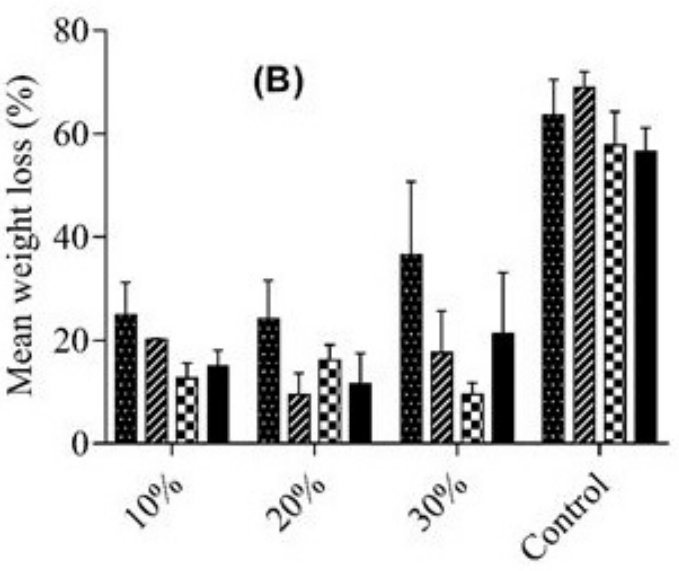

Concentration of heartwood extractives

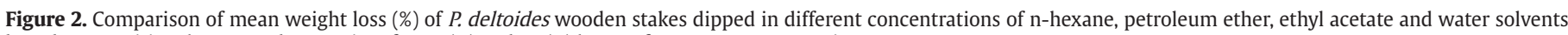
based $Z$. mauritiana heartwood extractives for 36 (A) and 72 (B) hours after exposure to termites. 


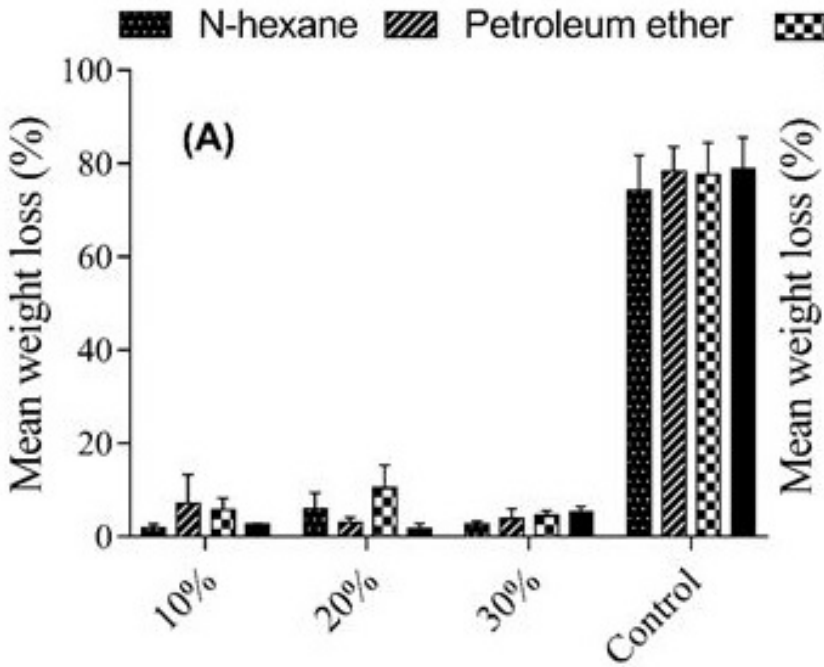

Concentration of bark extractives

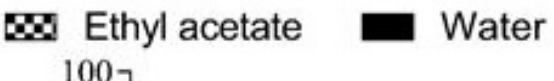

(B)

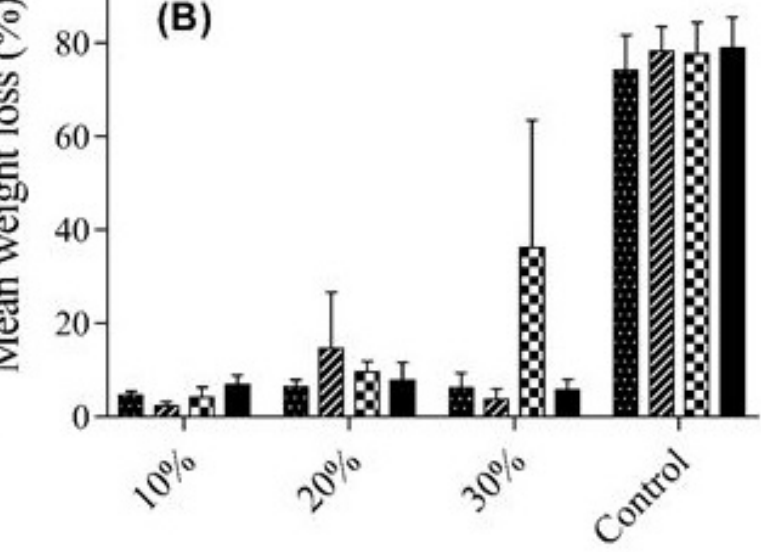

Concentration of bark extractives

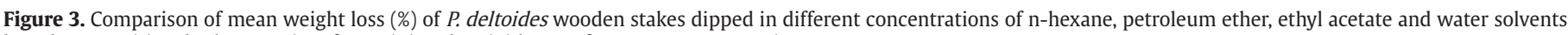
based $Z$. mauritiana bark extractives for 36 (A) and 72 (B) hours after exposure to termites.

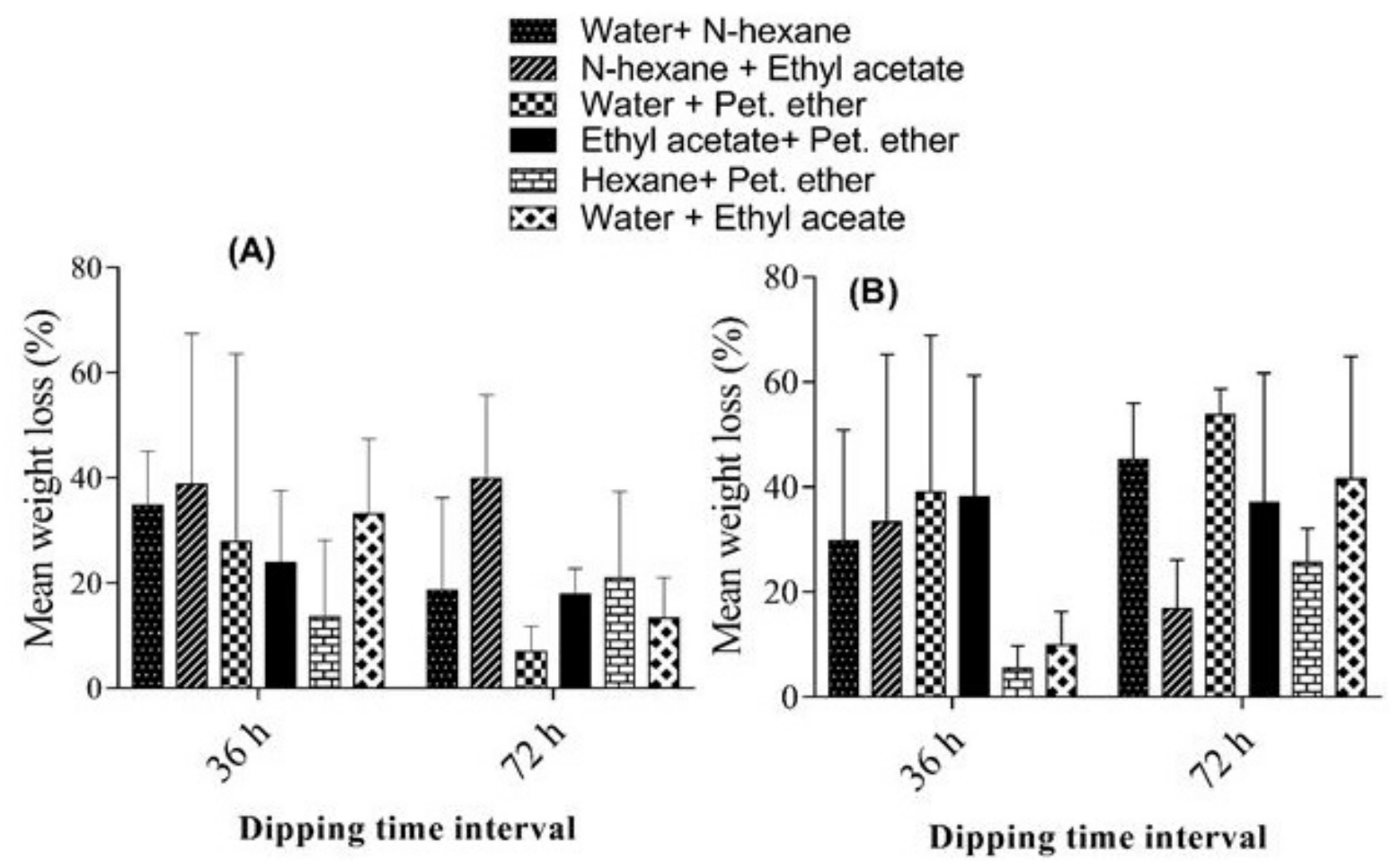

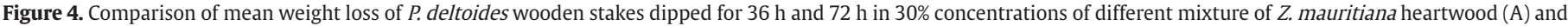
bark (B) extractives

acetate, water + pet ether, water + ethyl acetate, and ethyl acetate + pet ether) of extracts for 36 and 72 hours exposed to termites in field for 60 days is presented in Fig. 4 AB. There was no-significant difference in wood weight loss after treatment with heartwood extractives at each concentration $(F=1.33 ; p=0.29)$ for each type of extractives at each time interval $(F=2.35 ; p=0.13)$. Similar results were observed for bark extractives at each time concentration and time interval $(p>0.05)$. Maximum weight loss was observed in ethyl acetate ${ }_{+}$hexane based combination of extract which was not significantly different from rest of combination.
Results shows that when $P$. deltoides wood was oven dried at $80^{\circ} \mathrm{C}$ for seven days and then treated with heartwood and bark extractives. There was no significant difference among the different concentrations of each extractives from wood and bark except control treatment. Maximum weight loss ( $>70 \%$ ) was observed in control treatment of each solvent while minimum weight loss was observed in wooden stakes treated with pet ether at concentration of $30 \mathrm{mg} \mathrm{ml}^{-1}$ after seasoning $\left(80^{\circ} \mathrm{C}\right)$. Overall extract of $Z$. mauritania in hexane performed less activity against termites compared to other extractives (Fig. $5 \mathrm{AB}$ ). 


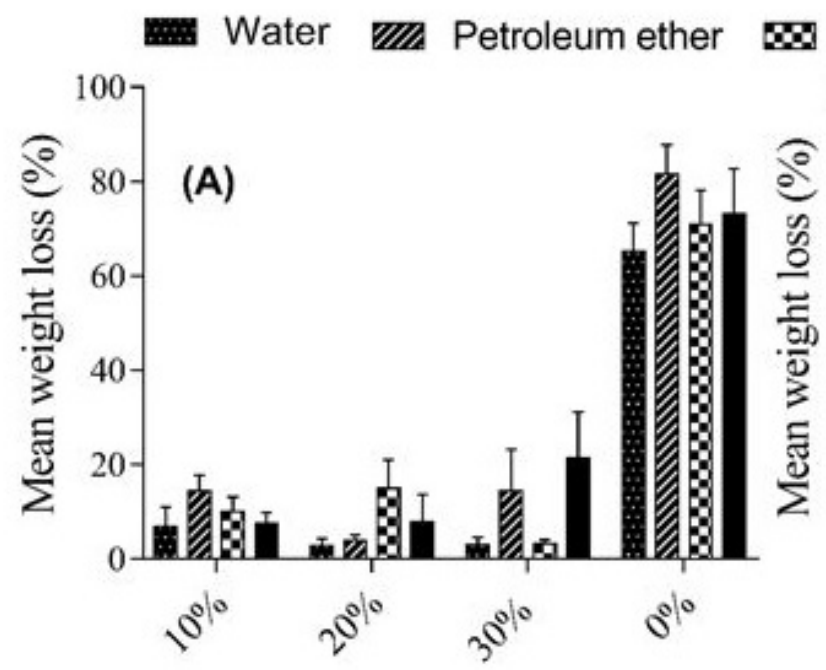

Concentration of heartwood extractives
Ethyl acetate N-hexane

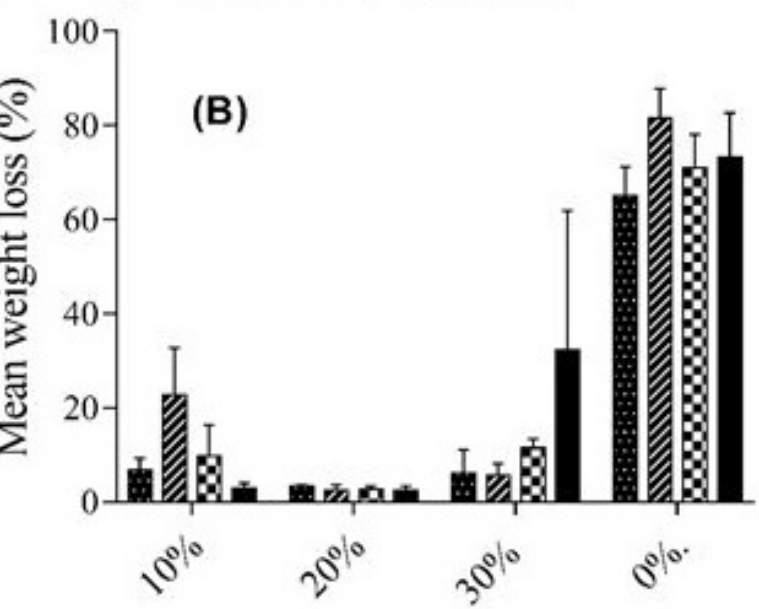

Concentration of bark extractives

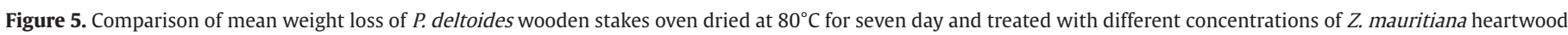
(A) and bark (B) extractives by dipping for $72 \mathrm{~h}$.

\section{Discussion}

The natural resistance of Z. mauritiana has been demonstrated by activities of heartwood and bark extractives in protection of a susceptible wood against termites in choice and no choice test. Maximum mean percent weight loss $81.1 \%$ was observed in case of $P$. deltoides. Weight loss of boiled $Z$. mauritiana was significantly higher compared to fresh + boiled + fresh $Z$. mauritiana $1.65 \%$, boiled + fresh + boiled $Z$. mauritiana $5.12 \%$, fresh+ boiled $Z$. mauritiana $4.53 \%$, fresh $Z$. mauritiana $3.31 \%$ respectively. Dugal and Latif (2015) reported another species Z. jujuba resistant to Coptotermes heimi and Heterotermes indicola along with several other trees including Mangifera indica, Erythrina suberosa, Betula utilis, Elaeis guineensis, Ficus religiosa, Heterophragma adenophyllum, Terminalia arjuna, Moringa oleifera, Putranjiva roxburghii, and Syzygium cumini.

Efficacy of heartwood extractives of $Z$. mauritiana showed antitermitic activities at $10-30 \mathrm{mg} \mathrm{ml}^{-1}$ and recorded lowest weight loss in susceptible wood of $P$. deltoides. Petroleum ether and aqueous extractives had maximum termiticide activity and lowest weight loss at the highest concentration on longer period of treatment (dipping in extractive solution) as compared to other extractives in various solvents. However, this was not the case in bark extractives. There was non-significant effect of dipping time on performance as wood protectant. Purpose of seasoning was to reduce the moisture content of tested susceptible wood and then determine the toxicity of extractives against termites. Results showed that there was non-significant effect of seasoning of performance of extractives against termites.

Previous studies showed that fruits, seed and wood of $Z$. mauritiana have high concentrations of phenolic compounds such as epicatechin, vanillin, quercetin, naringenin and Kaempferol in the extracts (Memon et al., 2012; Ashraf et al., 2015). Phenolic compound has been identified as inhibitor of detoxification enzymes in the termites' gut (Hassan et al., 2018a) leading to lethal effect on termites. Many extractives present in naturally durable wood are not only toxic to termites but are also a rich source of antioxidants/radical scavengers (Hassan et al., 2018a, b), which may act synergistically to affect termite mortality. Previous studies also showed that heartwood extractives from resistant wood containing flavonoid and terpenoids were toxic to gut symbiotic communities of termites (Hassan et al., 2017b) which is another reason of extractives being lethal to termites. Beside this, extractives of several wood species act as repellant against termites (Hassan et al., 2016).
Insecticide and repellent activities of parts of Ziziphus spp. Other than wood have been documented. Ethanol and pet ether extracts of $Z$. joazeiro and $Z$. jujube against mosquitoes species have been reported (Omena et al., 2007; El-Husseiny et al., 2014; El-Husseiny \& Ei-Kholy, 2015). Betulinic acid from the bark of $Z$. jujuba in acetone proved potent insect growth regulator and controlled Spodopetra litura effectively (Badathu et al., 2014). Lingampally et al. (2012) showed that a terpenoids from the bark of Ziziphus jujube acted as growth regulator against Tribolium confusum. Ahmad et al. (2011) revealed that crude methanolic extracts of aerial parts $Z$. jujuba were effective against the tested termites.

In addition, extracts of $Z$. mauritiana was also effective against microbes such as Escherichia coli, Staphylococcus aureus, Xanthomonas axonopodis pv, Bacillus subtilis, and Staphylococcus aureus, as well as anti-fungal activity against Dreschlera turcica and Aspergillus flavus (Najafi, 2013; Nkafamiya et al., 2013). Results of this study indicated that the transferring durability using toxic extractives from heartwood and bark of $Z$. mauritiana to non-durable $P$. deltoides improved the resistance against subterranean termites. Heartwood and bark extractives in petroleum ether had a significant negative impact on termite activity. These are foundational studies to establish biological relevance of the extractives from $Z$. mauritiana. Further studies are suggested to provide information about the active chemical(s) being toxic to termites which can be formulated wood protecting agent.

\section{Acknowledgements}

Authors are very thankful to the undergraduate students of Termite Research Laboratory, University of Agriculture Faisalabad, for their help during field experiments.

\section{Conflicts of interest}

All authors declare no conflict of interest for the manuscript entiltled “TERMITICIDE ACTIVITIES OF WOOD EXTRACTIVES OF Ziziphus mauritiana (Rhamnaceae) AGAINST SUBTERRANEAN TERMITES UNDER FIELD CONDITIONS" 


\section{Author contribution statement}

We confirm that this manuscript "TERMITICIDE ACTIVITIES OF WOOD EXTRACTIVES OF Ziziphus mauritiana (Rhamnaceae) AGAINST SUBTERRANEAN TERMITES UNDER FIELD CONDITIONS" by Zoulfiqar et al., is original and has not been published elsewhere nor under consideration by any other journal. All authors have contributed equally to the manuscript and approve of its publication in this journal. All experiments were conducted according to the laws of the country where they have been performed. To the best of our knowledge, everybody who participated substantially in the study is not omitted from the article and all persons listed as authors qualify for authorship

\section{References}

Ahmad, B., Khan, I., Bashir, S., Azam, S., Ali, N., 2011. The antifungal, cytotoxic, antitermite and insecticidal activities of Zizyphus jujube. Pak. J. Pharm. Sci. 24 (4), 489-493.

Ahmed, B., French, J., 2008. An overview of termite control methods in Australia and their link to aspects of termite biology and ecology. Pak. Entomol. 30 (2), 101-118.

Ahmed, S., Fatima, R., Nisar, M. S., Hassan, B., 2014. Evaluation of castor bean oil on Acacia nilotica as wood preservative against Odontotermes obesus (Ramb.) (Termitidae: isoptera). Int. Wood Prod. J. 5 (1), 5-10.

Ahmed, S., Hassan, B., Saleem, M. U., Riaz, M. A., Nisar, M. S., 2018. Efficacy of heartwood extractives of Albizia lebbeck (L.) Benth against subterranean termites. Int. Wood Prod. J. 9, 194-199.

Ashraf, A., Sarfraz, R. A., Anwar, F., Shahid, S. A., Alkharfy, K. M., 2015. Chemical composition and biological activities of leaves of Ziziphus mauritiana L native to Pakistan. Pak. J. Bot. 47, 367-376.

Badathu, M., Lingampallt, V., Kaur, V., 2014. Effect of betulinic acid on Spodoptera litura (Fab.) (Lepidoptera: noctuidae). Int. J. Sci. Res. (Ahmedabad) 8, 177-181.

Bajraktari, A., Nunes, L., Knapic, S., Pimenta, R., Pinto, T., Duarte, S., Miranda, I., Pereira, H., 2018. Chemical characterization, hardness and termite resistance of Quercus cerris heartwood from Kosovo. Maderas Cienc. Tecnol. 20, 305-314.

Devi, U., Bora, D., 2017. Growth inhibitory effect of phenolic extracts of Ziziphus jujuba Mill. in dengue vector Aedes aegypti(L.) in parent and F1 generation. Asian J. Med. Sci. 10 (8), 787-791.

Dugal, M. F., Latif, M. U., 2015. Comparative study of resistance and feeding preference of 24 wood species to attack by Heterotermes indicola (Wasmann) and Coptotermes heimi (Isoptera: Rhinotermitidae) in Pakistan. Sociobiol. 62, 417-425.

El-Husseiny, I. M., Ei-Kholy, S. E., 2015. The effect of jujube oil on some biological activities of Culex pipiens mosquito. J. Adv. Biol. 6, 1066-1071.

El-Husseiny, I. M., Ei-Kholy, S. E., Othman, A. A., 2014. Laboratory testing of the toxicity of jujube (Zizyphus jujuba) oil and leaf extracts against Culex pipiens (Diptera: culicidae). Afr. Entomol. 22, 755-761.

Hassan, B., 2017. Studies on the effect of wood extractives in combination with plant oil on subterranean termites. Doctoral of Science Thesis, University of Agriculture, Faisalabad Pakistan.

Hassan, B., Ahmed, S., Mankowski, M., Kirker, G., 2017a. Comparison of performance of wood extractives as preservatives in field tests against termites and decay in the USA and Pakistan. In: Annual Meeting American Wood Protection Association, 119, 2017, Las Vegas, NY. Proceedings. Alabama: American Wood Protection Association, pp. 29-38.
Hassan, B., Mankowski, M., Kirker, G., Ahmed, S., 2017b. Effects of heartwood extractives on symbiotic protozoan communities and mortality in two termite species. Int. Biodeter. Biodegr. 123, 27-36.

Hassan, B., Ahmed, S., Kirker, G., Mankowski, M. E., Ul Haq, M. M., 2018a. Antioxidant effects of four heartwood extractives on midgut enzyme activity in Heterotermes indicola (Blattodea: rhinotermitidae). Environ. Entomol. 47 (3), 741-748.

Hassan, B., Mankowski, M., Kirker, G., Clausen, C., Ahmed, S., 2018b. Effects of white mulberry (Morus alba) heartwood extract against Reticulitermes flavipes (Blattodea: rhinotermitidae). J. Econ. Entomol. 111 (3), 1337-1345.

Hassan, B., Ahmed, S., Ejaz, M. A., 2018c. Persistency of chlorpyrifos and termiban (imidacloprid) in soil against subterranean termites. J. Entomol. Acarol. Res. 50 (7735), 42-45.

Hassan, B., Mankowski, M., Kirker, G., Ahmed, S., ul Haq, M. M., 2016. Antitermitic activities of shisham (Dalbergia sissoo Roxb.) heartwood extractives against two termite species. In: Proceedings IRG Annual Meeting, 47, 2016, Lisbon, Portugal. Anais. Sweoden: IRG Secretariat, pp. 1-16.

Hassan, B., Ahmed, S., Mehmood, N., Mankowski, M. E., Ul Haq, M. M., 2019a. Toxicity potential of heartwood extractives from two mulberry species against Heterotermes indicola. Maderas Cienc. Tecnol. 21 (2), 153-162.

Hassan, B., Mankowski, M. E., Kirker, G., Ahmed, S., Bishell, A., 2019b. Ex-situ performance of extracts from naturally durable heartwood species and their potential as wood preservatives. Eur. J. Wood Wood Prod. 77 (5), 869-878.

Hassan, B., Ahmed, S., Kirker, G., Mankowski, M. E., ul Haq, M. M., 2019c. Synergistic effect of heartwood extracts in combination with linseed oil as wood preservatives against subterranean termite Heterotermes indicola (Blattodea: rhinotermitidae). Environ. Sci. Pollut. Res. Int. (in press). https://doi.org/10.1007/s11356-019-07202-7.

Islam, M., Shams, I., Ilias, G. M., Hannan, O., 2009. Protective antifungal effect of neem (Azadirachta indica) extracts on mango (Mangifera indica) and rain tree (Albizia saman) wood. Int. Biodeter. Biodegr. 63, 241-243.

Lee, S. H., Ashaari, Z., Lum, W. C., Halip, J. A., Ang, A. K., Tan, L.-P., Chin, K.-L., Ahir, P. M., 2018. Thermal treatment of wood using vegetable oils: A review. Constr. Build. Mater. 181, 408-419.

Lingampally, V., Solanki, V., Jayaram, V., Kaur, A., Raja, S. S., 2012. Betulinic acid: A potent insect growth regulator from Ziziphus jujuba against Tribolium confusum [Duval]. Asian J. Plant Sci. Res. 2 (2), 198-206.

Memon, A., Memon, N., Luthria, D., Pitafi, A., Bhanger, M., 2012. Phenolic compounds and seed oil composition of Ziziphus mauritiana $\mathrm{L}$. Fruit. Pol. J. Food Nutr. Sci. 62, 15-21.

Najafi, S., 2013. Phytochemical screening and antibacterial activity of leaf extract of Ziziphus mauritiana Lam. Res. J. Basic Appl. Sci. 4, 3274-3276.

Nkafamiya, I. I., Shagal, M. H., Haruna, M., 2013. Potential of Ziziphus spina-Christi seed ethanolic extract on inhibition of microbial growth. Acad. J. Biotechnol., 1 (4) 53-56.

Omena, M. C., Navarro, D. M., Paula, J. E., Luna, J. S., Ferreria, M. R., Ana, S., 2007. Larvicidal activities against Aedes aegypti of some Brazilian medicinal plants. Bioresour. Technol. 98, 2549-2556.

Ottosen, L. M., Ribeiro, A. B., Melcher, E., 2002. Polluted Wood Preservation Sites. Federal Research Centre for Forestry and Forest Products. Institute of Wood Biology and Wood Protection, Hamburg, Allemagne, $10 \mathrm{pp}$.

Razi, M. F., Anwar, R., Basra, S. M. A., Khan, M. M., Khan, I. A., 2014. Morphological characterization of leaves and fruit of jujube (Ziziphus mauritiana Lamk.) germplasm in Faisalabad, Pakistan. Pak. J. Agric. Sci. 50, 211-216. 